\title{
Challenges experienced by teachers regarding access to digital instruments, resources, and competences in adapting the educational process to physical distancing measures at the onset of the COVID-19 pandemic in Romania
}

\author{
Leyla Safta-Zecheria`; Sebastian-Aurelian Ștefănigă ‘; Ioana-Alexandra Negru•; \\ Francisca-Hortensia Virag ${ }^{\bullet}$
}

\section{Abstract}

Emergency remote teaching replaced face-to-face education almost everywhere in the world at the onset of the Covid-19 pandemic. Romania switched to online teaching in March 2020 as a recommendation that became an obligation to teach online in late April 2020. Teachers saw themselves confronted with the need to adapt to a completely new infrastructure for teaching and learning in the digital sphere. Building on qualitative data (interviews and focus groups), collected as part of a participatory action research project aiming to support school teachers in adapting to online education, we explore the question: How did teachers understand and respond to the challenges brought about by using digital instruments and resources in the educational process? Our findings show that teachers faced challenges in accessing technological and digital infrastructures, as well as in ensuring that pupils had access to online teaching and learning activities. Moreover, teachers were faced with the need to rapidly develop the digital competences necessary for online teaching. This prompted exchanges between teachers, pupils and parents, as well as the setting up of support structures within and outside school structures.

Keywords: digital competences, emergency remote education, access to education, digital resources, educational technologies

\section{Introduction}

The spread of the Covid-19 pandemic led governments across the world to take policy measures to minimize the spread and protect the lives and health of their citizens. Around the world, the suspension of face-to-face education has been a common feature of the first policy responses. This was visible, for example, at the peak of anti-Covid 19 preventive measures in the fact that more than $65 \%$ of the world's learners in 160 countries amounting to over 1 billion learners had had their face-to-face activity suspended by the beginning of May (UNESCO data, 2020a, for the 3rd of May).

In Romania, the suspension of face-to-face education on the 11th of March was decided by the by National Committee for Special Emergency Situations and was initially supposed to last only until 22nd March (Guvernul României, 2020). Yet, as it became clear that the situation was not to be solved within days, the State of Emergency was decreed

•PhD, Educational Sciences Department, West University of Timișoara, leyla.safta@e-uvt.ro

-PhD student, Computer Science Department, West University of Timișoara, sebastian.stefaniga@e-uvt.ro

- MA student, Educational Sciences Department, West University of Timișoara, ioana.negru97@e-uvt.ro

- MA student, Educational Sciences Department, West University of Timișoara, francisca.virag76@e-uvt.ro 
on the 16th of March. The decree also provided for a temporary and reasonable restriction on the right to education (Art. 2 and Art. 49 of the Decree instating the state of emergency, Decretul nr.195/2020). This framework created some confusion, since it involved a recommendation by the Minister of Education to continue the educational process online but without introducing new curriculum content (Ministerul Educației și Cercetării, 2020). More than one month later, on the 21st of April another approach was proposed that instilled an obligation to take part in online teaching, the parents and legal guardians are assigned responsibility for ensuring that pre-schoolers and pupils have access to online educational activities (OMEC 4135. 21.04.2020, especially Art. 11, available here).

Although formally acknowledging, as well attempting to solve the problem of access to education in the online environment, the policy response left many questions unanswered: How is the shift to online teaching and learning experienced on the ground? What are the challenges in terms of ensuring access to quality education online that teachers are confronted with? Are digital resources and instruments available and accessible to teachers and pupils? And how are they understood and used by them?

In this paper, we answer these questions by looking at qualitative data generated as part of a participatory action research project based at the West University Timișoara. Specifically, we focus on seven semi-structured interviews with teachers, as well as two focus groups with teacher participants. The participatory action research project aimed to support teachers in the transition to online learning by responding to their needs as they arise. All support and research activities were carried out at a distance, mostly online, but also on the phone.

\section{Ensuring access to education during the suspension of face-to-face activities in schools as a measure to limit the spread of Covid-19}

The educational policy measures put in place to slow down the spread of Covid-19 have given rise to significant challenges to educational systems and practitioners across the world. UNESCO estimates that 24 Million learners across the world are in danger of not returning to school in 2020 (UNESCO, 2020b). Of these, many are university students, nevertheless, a significant proportion is made up of school-aged children and young people. Significantly, those with no access to education during physical distancing measures are more at risk of not returning to school (UNESCO, 2020b). Moreover, physical distancing measures and the sudden switch to online teaching and learning are likely to have a negative impact widening already existing socio-emotional, as well socioeconomic gaps between pupils (Pietro et al, 2020).

While, for pupils the risk of not returning to school because of loss of contact with the school environment persists, teachers need to rise to the challenge of ensuring quality remote education in an emergency context. As has been recently pointed out, emergency remote teaching (Hodges et al, 2020) is very different from distance education and should not be assessed according to the same criteria. The challenges of re-organizing school- 
based educational activities in a remote manner, when they were explicitly designed to be carried out in a face-to-face environment, requires setting up innovative support structures for teachers (Pietro et al, 2020). In Romania, this has meant teachers and students have been faced with the absence of a technological infrastructure, the lack of digital competences and the lack of access to educational software platforms (Botnariuc et al, 2020). The lack of guidance as to which software platforms to use and the lack of a unitary approach to the transition to online learning have also been a marker of stress for many teachers (Edumanager, 2020). Recent research in Romania has nevertheless also shown that students of educational sciences programs across the country have a significant level of competences relevant for digital education and therefore can constitute a significant resource base for facilitating the transition to online education (Alexandru et. al, 2020).

Digital competences proved to be essential in the transition to online education. As has been previously pointed out (Røkenes \& Krumsvik, 2014) it is useful to understand digital competences for teachers and students/ pupils broadly as "skills, knowledge, creativity, and attitudes that everybody needs in order to use digital media for learning and functioning in the knowledge society" (Erstad, Kløvstad, Kristiansen, \& Søby, 2005 translated in Røkenes \& Krumsvik, 2014, pg. 252). This definition allows to investigate digital competences not just as digital literacy, but as a wide range of competences that may incorporate pedagogical, as well as sociological competences relevant for using technology in education (Røkenes \& Krumsvik, 2014).

\section{Methodology}

\section{Participatory Action Research Design}

The present paper is based on a participatory action research addressing the challenges faced by teachers while adapting the educational process to physical distancing measures imposed by the Covid-19 pandemic.

Participatory action research is a research methodology that involves investigating a relevant and pressing issue for a community together with its members and has been used successfully to improve education since the 1950s (Paz Morales, 2019). Although participatory action research has worked as a complement to professional learning and development for teachers (Paz Morales, 2019), it is only now beginning to be used to understand and facilitate the active learning and professional development of educators as they adapt their practices to the exigencies of transitioning to online learning (Avgerinou \& Moros, 2020).

The present project started from the impulse to offer support to teachers in view of the challenges that they were facing in adapting to online teaching and learning. At the onset, all interested students of the department of Educational Sciences at the West University of Timișoara (WUT) were offered webinars about adapting the educational process to online learning and in how to use specific software programs for online 
education (Zoom, Kahoot, etc.). After two intense webinar sessions (held in several series to accommodate multiple participants), the students were then asked whether they wanted to participate as volunteers in a tutoring program offering support to teachers in transitioning to online learning. Around twenty students of the more than one hundred total webinar participants agreed to take up this role, with around ten students engaging over a period of several months. At the same time, principals were contacted from schools in the wider educational community around WUT and offered the opportunity to advertise the tutoring program to teachers in their school that could need support. A number of thirty-seven teachers were initially registered for the program and more than half of them participated actively throughout the tutoring process. The teachers came from very different schools including well equipped downtown schools in Timișoara, as well as schools in the rural area. The teachers that participated in the tutoring program were of different ages, levels of seniority and genders, and catered to differently aged children (from primary school to high-school) and came from different Romanian counties, mostly in the North-West region.

Parallel to and connected to the tutoring program, we also set up a research initiative. All student tutor-volunteers were invited to take part in the research component, but only seven students consented to be involved in this process. The point of the data collection was to identify the challenges teachers were faced with in order to better respond to their learning needs, as well as identify potential medium and long term challenges, and issues that needed to be addressed through different interventions (policies, learning and professional development, etc.).

\section{Research instruments}

To document the challenges, tutors were invited to submit anonymous reflexive journal entries through a google form after offering support. Moreover, two focus groups with tutored teachers were organized virtually in May 2020 where we took stalk of how the challenges of transitioning to online had been experienced by teachers and how the program could improve its response to these challenges. After the end of the school year, in summer 2020, seven teachers and four school principals, as well as four tutors were interviewed about their understanding of the transition to online learning, the challenges they experienced and how they had experienced the tutoring program.

The interviewees and focus group participants had all been involved with the project and therefore a trust relationship had been established with them through the tutoring program, contributing to their willingness to participate in this process. The interviews were semi-structured and took place virtually (only one interview was carried out over the phone, since the interviewee did not have access to a proficient internet connection). The duration of the interviews was approximately ninety minutes and all interviews were (audio) recorded with the permission of the interviewee. The interviews were either transcribed during the interview by another member of the research team and edited retrospectively or were transcribed after the interview based on the recording. The 
transcripts were then anonymized. Only the written anonymized transcripts were used for the analysis.

Two types of instruments were used in collecting the data analyzed here: semistructured interviews with teachers and focus groups with teacher participants. We interviewed seven teachers aged between 20 and 55 as follows: two teachers aged between 20 and 40, three teachers aged between 40 and 50 and two teachers aged between 50 and 55 .

Of those mentioned three have a seniority in education of up to 10 years, one of 14 years and three over 20 years. The teacher with the least seniority in education has 2 years of experience in education and the most experienced teacher has 33 years. From the perspective of the subjects taught, five of them teach at the primary school level, one teaches Romanian Language and Literature, and one teaches Mathematics, Physics and Chemistry. We need to mention that four teachers teach in urban areas and three in rural areas.

The semi-structured interviews were made up of five sections each addressing a different topic. The topics were: (1) the challenges of physical distancing measures applied to education, (2) the timeframe of online teaching experiences, (3) online teaching methods, (4) classroom management and (5) learning and professional development. A total of 21 open-ended questions were asked, each was operationalized through a series of follow-up questions that depended on the interviewees responses. Some of the main questions were followed by no less than 10 follow-up questions, while others were followed by only 2 additional questions.

Two focus groups were carried out online via Zoom and through incorporating questions in the interactive software Mentimeter: in the first focus group, five teachers participated, in the second, four. Tutors participated in the focus groups as well, but their answers were not relevant to our present inquiry. All teachers that received support as part of the tutoring program were invited to both interviews and focus groups. Nevertheless, some only participated in the interviews and some only in the focus groups with a small number that likely participated in both. Each focus group had different participants, except for the three focus group facilitators, faculty members of the Department of Educational Sciences at West University of Timișoara. The focus group duration was 90 minutes for the first focus group and 100 minutes for the second focus group. The focus groups were based on each participant presenting their experience during the program and the transition to distance learning, elaborating on certain issues through follow-up questions from the facilitators (such as the difficulty of conducting online assessment, modifications in the legal framework etc.), a number of questions were administered via the interactive software mentimeter to capture the reactions to transitioning to online, as well as the assessment of the tutoring program, and the way in which teachers plan to use technology in an educational in the future. Teachers engaged with each other's answers throughout the focus groups, complementing or contradicting each other with examples from their own everyday experience. 


\section{Research objectives and questions}

The (entire) research project had as its main objectives to document:

01: How teachers experienced challenges of adapting to physically distanced educational activities

02: How teachers understood (or made sense of ) these challenges.

In this research paper, we engage with a series sub-issues that were proved to be particularly salient during the data analysis phase. For this paper we thus set the following objectives:

Objective for this research paper 1(ORP1): To document how teachers viewed the way in which the educational process was affected by the question of access to digital instruments and resources for the educational process.

ORP2: To document how teachers viewed the way in which the educational process was affected by the question of access to digital competences necessary for conducting and participating in online educational activities.

Although potentially relevant, the data concerning how teachers perceived the support offered during the tutoring program is not analyzed here, as it will likely form the object of future analysis.

In the following we explore the research questions:

RQ1: How did teachers understand the challenges brought about by using digital instruments and resources in the educational process?

RQ2: How did teachers respond to these challenges?

\section{Coding and analysis}

We have chosen to focus on the teachers' perspective that is why we have selected for analysis the two focus groups, as well as the seven interviews with teachers. The chosen data was coded (Saldana, 2013) inductively in a first round that was organized collaboratively. The emerging codes were discussed at weekly meetings, after each meeting everyone in the small research group that worked on this paper was invited to revisit portions of the data to apply the collectively agreed upon codes.

For the present analysis, the team first decided on a common topic that had come up in the data and has significant relevance for understanding present challenges: the sudden digitalization of the educational process in the early days of the pandemic. We decided to explore this topic and see which codes appear in relation to it. Based on a subsequent round of coding and discussion, we agreed to explore the issue of challenges for access to the educational process as mediated by two different processes: (1) the access to technological and digital infrastructure and (2) developing digital competences of teachers, pupils and parents. 
The relevant data was then analyzed and written-up collaboratively. The collaborative process was organized at a distance, through using video conferencing software and collaborative document editing platforms.

\section{Findings}

As mentioned above, here we present our analysis of how teachers perceived the challenges for access to the educational process as mediated by two different processes: (1) the access to technological and digital infrastructure and (2) developing digital competences of teachers, pupils and parents. Our analysis connects to our two research objectives outlined in the methodology section: (1) refers to ORP1 and (2) refers to ORP2. The objectives for this paper were developed inductively after first coding the qualitative data that we had set out to explore starting from the research questions proposed in this paper. Therefore, the research objectives and research questions relate in a transversal way: the objectives are the result of an inductive coding process and not the starting point of a deductive hypothesis-testing inquiry.

\section{1) Challenges regarding the access to technological and digital infrastructures} necessary for participating in the educational process

The access to technological and digital infrastructure refers to how the challenges of getting pupils and teachers connected online made visible the disparities of technological infrastructure and those of access to digital resources.

\section{(a) Access to technological infrastructure}

Technological infrastructure involved both the hardware (phones, laptops, etc) and the technical infrastructure of connectivity (internet access, electricity, etc.). Teachers were confronted with difficulties in ensuring that all pupils (can) attend their classes because of problems with the technological infrastructure. This was understood as happening either because the pupils' families did not have the means to provide them with access to technology during the day (while at work) or at all or because of connectivity (mainly internet access) and other technological issues. In the focus group, those teachers that were teaching pupils that had both access to a laptop and internet considered themselves to be lucky pointing to the fact that they considered this to be the exception rather than rule. In some cases, even half of the class could not attend online educational activities on a regular basis. One of the teachers interviewed mentioned that lack of technological access wasn't the only reason some pupils could not attend but saw the lack of participation as connected with instances of poverty. Another teacher mentioned lack of intrinsic motivation, stating also that the lack of an obligation to attend online classes might have had an impact on certain pupils' willingness to attend.

Another teacher participating in one of the focus groups mentioned pupils in her class that couldn't attend online classes:

[The] girl doesn't have the technology, she doesn't have the means for it, the mother has four children and she couldn't do it [have them attend online classes] for all of them, so she decided none of them should attend. But we work on WhatsApp. We go on, I send things 
on WhatsApp and she is not excluded from the lessons and from what happens in the online school.' (participant in focus group)

Other teachers even mentioned working with different software platforms that required less technological infrastructure as a strategy for reaching a higher number of pupils, as this teacher who works in a rural area mentioned during the focus group:

'Yes, there are some [pupils] that we couldn't connect to via Zoom, but we did via messenger, we keep messages, sometimes we work on Zoom and messenger, work from the laptop but also from the phone, this is how we tried to reach as many children as possible.'(participant in focus group)

Moreover, even when the online connection between pupils and teachers was possible, the technological infrastructure negatively affected the communication process, influencing how much the teacher could understand from what was actually going on, on the other side of the pupils' screens:

'It happened that they couldn't hear me or that they would hear me in a loop, they couldn't follow what I was saying, there are many pupils, I couldn't monitor them very well, when they should have been working, they would disconnect their images [cameras] and I wouldn't know what they were doing. I would mention [muting] the microphone, but they would also disconnect the [camera] images and I don't know what they were doing, probably they were also doing other things." (P_MB_AM_17072020)

This problem also existed the other way around: if teachers' own personal technological equipment was not up to date, this would affect the communication process, a problem shared by several teachers. A young teacher (aged twenty-five) described this as follows:

'I have one [a smart phone] that I work from, but the camera is not very good. Since I work from my phone, I cannot see all of them at once. I only worked from my phone; I didn't work from the [a] laptop.' (P_IN_VF_15072020)

This issue was connected mainly to the personal resources that the teachers had access to. For example, one teacher received a laptop from her son to be able to teach online, while her daughter (with whom she previously shared a laptop) attended online classes:

'The first time, I admit, we had only one laptop that my daughter and I were fighting over. She is a student and she started online classes immediately [...] and I would say, give [the laptop] to me, I also need to hold my classes. And then my son also bought me a laptop [...] so that we wouldn't fight over it anymore." (P_VO_VF_14072020, aged fifty-three, teaches math and physics in a rural area)

Another teacher mentioned in the interview that she was glad that she had everything she needed to work from home, including a scanner and a copy machine (P_TM_AM_28072020). Yet, it is unclear how many teachers benefitted from comparable technological infrastructures necessary for carrying out online educational activities. 


\section{(B) Access to digital infrastructure}

The question of digital infrastructure was often articulated by our interviewees together with that of digital competences. Teachers chose to refer to access to digital resources for teaching and learning together with the need to develop the necessary skills to use these applications. In some instances, teachers could choose the resources they wanted to work with, but needed to identify these resources on their own, in other cases the schools' principals decided what platforms should be used, but did not always provide guidance on how to use them. Even when teachers identified adequate resources online, they were not always satisfied with the results:

II used Zoom, Google Classroom, WhatsApp, [the] phone, I used everything that could be used. I identified the resources myself on the internet, [taking advice] from the school, from my colleagues. I also used videos found on the internet. I consider that digital resources responded only as educational material, but I wasn't satisfied with what happened and what I had to use.' (P_TM_AM_28072020)

Later in the interview, the same teacher explained that she felt a significant difference in communication between talking to pupils and parents face-to-face and just sending different materials and worksheets online.

Another issue mentioned in relation to this was that of a perceived need for official guidance in selecting appropriate resources that should also be recognized administratively by the school leadership or by the Ministry of Education as adequate for use in transferring the educational activity to online. This was felt by some (but not all of the teachers), as this teacher explained:

I didn't want to learn too many [online platforms and resources that can be used in education]. It's better if I learn one or two, but those should be really good. There was no point in using ten platforms at once and overwhelming everyone and the kids [...] It was a problem to install so many apps on their phones, it was difficult. [....] It was important that what we do is official. Because until everything was official since the 11th of March [the onset of the recommendation but not obligation to teach online] each of us [teachers] did what (s)he could: used WhatsApp, Skype, Messenger. My phone was full of photos of homework.' (P_VO_VF_14072020)

Another teacher from an urban area saw this lack of official guidance as both an opportunity, as well as a problem since it could be misused to avoid carrying out educational activities:

'It was a total transition to the digital [sphere]. Part of it was more searching, exploring. We were not really guided very much... at least at the level of the school we were not asked "do this, do that". There was a lot of freedom and this was good in a way because there was no pressure and no strict control. But it was also bad in a way because I had colleagues that did absolutely nothing. I mean they sent some [learning] material and then sent again some [learning] material and then [it was time for] holiday.' (P_MP_VF_15072020) 
Nevertheless, in some cases teachers built their online activities on previously used apps, such as WhatsApp, as well as on newly identified educational platforms that they started using after consulting with the tutors in our program:

I tried at each class to use videos about the lessons, I also received a lot of advice from the tutor. With [their] support, I identified the [online] resources. I worked on my phone, laptop by using Google Classroom, [...] Google Meet, and WhatsApp, which I also used before the pandemic. The school provided us with Google services for virtual classes. The school's resources were useful as an emergency solution, unfortunately these were not very useful for primary school pupils [First Grade]. The pupils don't have their own devices, but they use their parents' devices. [...] I was online everyday with them [pupils] and I had 6-7-8-9 [pupils] at the time set in the schedule. Besides them [pupils], during the classes, parents and grandparents and neighbors were also present and it wasn't the ideal learning environment. I say that in the case of primary school it [online learning] is not the ideal solution, only in the emergency situation [of the pandemic it is acceptable]. (P_TM_AM_17072020)

The same teacher also mentioned using the digital version of school textbooks and its extra online features such as videos as very useful. On the opposite end, another teacher mentioned not using the school textbooks as an advantage in adapting her educational activities to online:

'To me it was really helpful that I had [educational material I had developed previously]. I do not use the textbook almost at all. I create a lot of worksheets that I find more appropriate or more fitting to the [skill] level of my pupils. And then, since they study at a technical school, the level is very low and sometimes textbooks require very abstract things or too boring things to them, and everything needs to be simplified. The fact that I had all these resources ready for years helped me very much, because I didn't need to make new ones, and even though I did make new ones, it helped me enormously that I already had some resources ready. And a teacher that works with handwritten notes or the textbook, practically, (s)he starts from scratch with no materials and this is a big barrier.' (P_MP_VF_15072020)

\section{Conclusions on (1) access to technological and digital resources}

Teachers were faced with needing to adapt not only to teaching online, but also to the different technological possibilities available to pupils in the same class or school. This meant providing differentiated educational materials through different software platforms depending on whether they were more or less resource intensive. Teachers also had to use their own technological resources to carry out the educational activities and their access to these resources varied greatly and depended mostly on their personal networks. All teachers interviewed were not only concerned with adapting their activities to the online environment but also with identifying adequate digital resources and platforms that were also accessible to their pupils. In switching to online education not only educational activities, but also worksheets and supporting materials needed to be adapted. 


\section{(2) Developing digital competences of teachers, pupils, and parents}

From the perspective of digital competences of teachers, pupils and parents, an important issue that was perceived as a challenge for teachers was using software and online platforms for educational purposes. In this respect the tutoring program wanted to create an open learning environment in which the teachers' concrete action and learning needs would be addressed. Many of the participating teachers in interviews and focus groups mentioned learning how to use digital platforms from their tutors. Here we address other forms of competence transfers and learning processes that were mentioned by the teachers.

The underdevelopment of digital competences both in the case of teachers and pupils, but also in the case of parents, posed significant challenges to the teachers in their attempts to adapt their activity to online teaching and learning. Parents' digital competences were also important since they played a key role in facilitating access to the educational processes.

\section{(a) Teachers' digital competences}

Understanding which digital resources to use in online teaching was perceived as a challenge, also in view of planning and structuring the educational process. Some teachers saw adapting to online teaching and learning as a necessary measure in the crisis situation brought about by the onset of the pandemic and considered the need to acquire new digital competences as part of this process of adapting to the crisis situation by hard work and being able to teach yourself the necessary skills, as well as by further developing communication skills:

'Digital pedagogy is suitable in the pandemic context. It was appropriate to replace face-to-face education. [...] A teacher should have more digital skills [for online teaching]. I believe that anything can be learned if the teacher is truly involved in the process. He needs to know the minimum to be able to use the computer and I don't think it's so complicated to use it. Anyone and any teacher can learn if he/she wants. I consider that communication competences in the online environment are particularly necessary [at the present time].' (P_TM_AM_28072020)

Another teacher spoke of digital pedagogy as a field that was difficult to understand, she also complained about the differences between face-to-face and digital communication:

'The difference between digital and physical [teaching] is face-to-face personal communication and physical contact. Everything is impersonal [in the digital sphere].' (P_TM_AM_17072020)

Teachers came to be concerned whether parents and pupils would be overwhelmed by the number of digital resources needed for the educational process and by the competence demands that these involved:

It was a challenge to learn how to work online at the beginning of my teaching career, to learn so many things on [online educational] platforms, to structure all my lessons in this 
way, to teach, to evaluate. It was a challenge to communicate with parents. I was afraid in the beginning that they wouldn't understand so many things: the WhatsApp group and getting all the children's phone numbers that I didn't have, the Google Classroom platform, setting up all the accounts, then working on Zoom and so much more.[...] I was surprised how fast and flexible the parents were." (P_IN_VF_15072020, twenty-five years old, four years of teaching experience, primary school teacher, in an urban school)

During the transition to online learning the planning of educational activities was affected, as time management came to be increasingly unpredictable:

In online teaching I would think one day in advance what I will teach, I would make a sketch of my classes, I would do the math exercises to not have difficulties the next day and know how to explain them, but I did not have a lesson plan [....].' (P_IN_VF_15072020)

In a similar vein, another teacher mentioned that time had come to be a significant problem in online teaching since it was harder to anticipate what was going to happen during class:

'Firstly, a lot of time is wasted [in adapting educational activities to the online environment], because you can't control the part [what is going on] behind the screen and you can expect unforeseen things. I say that time is the resource that is lost the most [in this process].' (P_TM_AM_17072020)

One of the teachers connected the challenges of developing the digital competences necessary for online teaching to their perceived lack of skills in other fields, for example, English language skills. In this instance, the need arising from the present situation is seen as an opportunity to develop digital competences despite these impediments, as is apparent from this quote from another interview:

I think basic [digital competences are necessary to be able to teach online]. You can see how easily I can speak now [in an online environment]. But had you asked me three months ago, I wouldn't have known which button to press. Instead of turning on the camera, I would turn it off, and so on. Because I don't know English, [...] I needed to pick up the words as I went on. Anyone can 'turn on', 'access', 'share' [word in English in original], maybe there are competences that I didn't discover, but these are enough for me.' ( $P_{-} V O_{-} V F_{-}$14072020)

Challenging as it was, developing digital competences during this period was also perceived as an opportunity for learning and development by several of the teachers interviewed. For example, this forty-two year old primary school teacher perceived this time as follows:

'[I learned] very many things, especially connected to IT [software]. Like making short movies, putting information together and here I am not speaking of assignment sheets, since I would do those anyway. From creating tutorials to the social experience that I acquired in the educational system.' (P_AB_VF_15072020)

While many teachers spoke of their newly developed digital competences, some mentioned formal training they received in this field that goes back as far as the year 2000 and that they could successfully incorporated into the educational activities online. (P_TM_AM_28072020) One of the teachers mentioned already having some of the 
competences necessary for transitioning to online. Nevertheless, she still had to adapt to new resources and instruments and learn how to use them when the school introduced its own set of instruments to be used:

'As a Teach for Romania alumna, I knew Zoom and we were already using Zoom for different meetings with alumni and such things. So, using Zoom came quite naturally and in the first part I used Edmodo because it was already being used. After that the school moved, so we all moved, Microsoft Team[s] accounts were set up. That took some time. We only got to use them after Easter [when the obligation to teach online was in effect]. But when everyone was on [MS] Office, [...] basically, I replaced Edmodo with Microsoft Office.'(P_MP_VF_15072020)

The same teacher even mentioned being overwhelmed by the amount of online support that was coming from everywhere. Although this was in no way typical of other people's experience, nevertheless it is an interesting perspective:

[Support] came from everywhere. You would barely open Facebook and you'd see 10 tutoring videos, course advertisements and the like.' (P_MP_VF_15072020)

Developing digital competences and setting-up the digital infrastructure gave rise to support structures within the school as well. In one of the schools, where the teachers we worked with were working, the educational-methodological commission at school level set up a virtual group, where members could share resources:

'We had a group that was part of our school's educational-methodological commission that would send us all sorts of links, whatever they would find and even at school level we had links being sent in our teachers' group. Every one of us would bring something new to the group.' (P_AB_VF_15072020)

In another school, the digital infrastructure was set up with the help of administrative staff from the school:

'The school's IT specialist helped us set up our Google Classroom accounts and then I learned how to work on Zoom.' (P_IN_VF_15072020)

Furthermore, teachers started to become aware of opportunities to develop digital competences relevant to conducting educational activities online through informal learning by observing other educational practitioners and how they teach online:

I take part in [a teacher training course, name was rendered anonymous], it is not about digital resources. [...] It is helpful since the trainer uses many apps that we [the participants] have never even heard of, and we keep asking her "Mrs., where did you find them?" I made an entire list and after her class is over, we just navigate through them and think, oh, I will use this. Apps are very important, to me at least.' (P_VO_VF_14072020)

Nevertheless, not all exchanges and experiences regarding carrying out online activities were positive. One of the teachers even felt that some people felt threatened by other teachers' online educational activities:

'In the teachers' office [meaning the teachers from the respondent's school] it didn't really exist. There people were trying to do the bare minimum and when they would see other people posting and you could tell they were doing something; I think they felt 
threatened and they were wondering why are people trying to do more than what is required at the minimum level.' (P_MP_VF_15072020)

\section{(b) Pupils' and parents' digital competences}

The necessity to adapt to teaching and learning online has brought an impulse to unexpected forms of transfer of competences between pupils and teachers and back. As this science teacher from a rural area explained in the interview:

'They [the pupils] use technology and this is the present and the future. Children are very skilled, they adapt quickly. They were even teaching us [teachers]. They would say Mrs. [teacher] press that button that's the one you need.' (P_VO_VF_14072020)

At another moment during the same interview, the teacher mentioned the reverse process in terms of competence transfer:

'All the kids from the school would ask me and after I had learned, you guess how good that felt, "Mrs., how can I register an account here? Mrs., I can't get in", "Did you get a Gmail account? blah, blah". So, after I learned this, I was a very good... teacher.' (P_VO_VF_14072020)

Pupils' digital competences and infrastructures are not always compatible with those necessary for online educational activities, as this teacher explained:

'First of all, you need to have and to know how to use an email address. This might appear as a small thing, but the majority of pupils do not have email addresses, because they don't need them. Already on the social media networks they are using, they can set up an account using their phone numbers or who knows what and many do not have an email address and do not use it either. They set up an email address once to do who knows what, they forgot the password and that was it. No one sends them emails'. (P_MP_VF_15072020)

A teacher referred to the way in which pupils were developing digital competences as 'learning through trial and error' (P_TM_AM_28072020). Nevertheless, the optimism surrounding the competence development should not be overstated. While online teaching and learning is understood as enabling digital competence development, it is also seen as potentially creating gaps in assimilating the regular curriculum that may become visible when face-to-face learning replaces online learning once more. Some teachers were also explicitly concerned about the lack of preparedness of pupils for online forms of teaching and learning (P_TM_AM_17072020).

Another point that was mentioned as a potentially problematic aspect of online teaching and learning and the digital competences this process requires is connected to younger primary school pupils that lack digital competences and need parental support to attend classes online, in the words of a focus group participant:

'It was quite difficult since I teach first graders, children depend on the phones, they don't do the work, they are helped by parents, mothers, which is not ideal. You cannot replace what is happening in the classroom, especially when it comes to small children. [...] They don't know how to use all the functions of the apps, they send me a wave, a flux of homework.' (focus group participant) 
Parents' aid was crucial not only for helping pupils participate in online educational activities, but also in helping teachers set them up. One of the teachers even mentioned that a parent was the person who set up her Google Classroom account during one of the focus groups. This points to the issue of how online teaching and learning has reconfigured the relationship between teachers, pupils, and parents, an issue that we cannot explore at length here.

\section{Conclusions of the (2) teachers', pupils', and parents' digital competences}

The switch to online educational activities involved a need to rapidly develop basic digital competences of teachers, pupils, and parents. This meant an increase in parental involvement in school learning needed especially for online educational activities in the primary school. It also meant that teachers needed to learn from pupils, as well as the other way around and that all groups needed to support each other to ensure that online educational activities could happen. Nevertheless, some teachers still perceived the online environment as impersonal and communication, and more specifically feedback as more difficult to carry out online.

To facilitate the process of acquiring digital competences, support structures were created both within and outside schools. Nevertheless, some teachers still felt they received too little formal guidance on what digital resources to use and how. Among the less predictable challenges to adapting to online, we can mention that some teachers felt time management (in terms of lesson planning) to be increasingly difficult and the fact that other skills (such as English language skills) were also sometimes a necessary prerequisite to developing digital skills.

\section{Conclusions}

Teachers experienced several challenges in adapting the educational process to physical distancing measures at the onset of the COVID-19 pandemic in Romania. Significantly, they were faced with challenges regarding access to technological and digital instruments. They needed to use their own personal equipment, and infrastructures, and these were not always proficient and the access to them depended on their own personal networks. But even those teachers that did have access to equipment and a good internet connection faced challenges in ensuring that all the pupils in their classes could attend online educational activities. This resulted in teachers adapting not only to online teaching, but also to using multiple software platforms at the same time, ensuring that educational content could be accessed by only using a (smart) phone to those students that did not have access to proficient technological infrastructures.

The fact that the educational process was accessible to different pupils through different platforms should not create the impression that the same quality of education could be provided to all. It should be understood that merely a very important form of 
basic inclusion and connection to the educational environment of the school was maintained. Access to high quality technological infrastructure for teachers, pupils and parents and respectively the lack thereof is very likely to create inequitable outcomes in respect of how much learning could occur during the phase of physical distancing in education. These outcomes may also occur between highly motivated pupils and pupils that are less motivated in the process of learning, irrespective of their access to technological infrastructure. These forms of inequities will be especially relevant when thinking about national and standardized international (PISA, TIMSS, etc) examination outcomes in future years regarding the cohorts that are now in schools.

Besides having access to technological infrastructures, teachers needed to identify and learn which digital resources to use for education and how to manage the online learning process. This involved developing basic digital competences under pressure. This process meant that both teachers and pupils learned from each other how to use technology for education and that parents became increasingly involved in constantly offering support to pupils and occasionally to teachers. This process of mutual learning also opens up the question of what happened in the environments were neither teachers, nor pupils or parents had basic digital competences at the beginning of physical distancing measures. We have not encountered such perspectives in our research, but this likely due to the fact that our participatory action research project also offered precisely the kind of support needed to develop the necessary skills for online teaching and learning while these competences were being transformed into a necessity.

Other online support networks developed during this period, both in schools and outside of them. Nevertheless, teachers felt they needed more formal and informal guidance in how to use technology and digital resources for education. Teachers felt they needed to adapt their teaching and assessment styles, to restructure their courses and to find solutions to motivate pupils to participate in their classes. If teaching methodologies appeared to be relatively easy to rethink, the absence of an online assessment methodology that would either be framed as a requirement or a suggestion was very strongly felt by teachers.

At the onset of the pandemic in Romania, the recommendation to continue teaching in an online environment that coincided with the suspension of face-to-face activities in schools (mid-March) brought about very different reactions on the side of teachers. Some of the teachers wanted to continue teaching online by using video-conferencing software and other technological infrastructures that allowed similar interactions to those that would happen face-to-face in a school setting, while others preferred just to send learning materials online, while others did not consider they needed to continue teaching in any way. This increased the insecurity experienced by teachers that continued teaching and they came to ask themselves whether what they were doing was alright or not. In the absence of clearly disseminated online teaching and assessment methodologies, teachers were left to evaluate the learning outcomes of their practices on their own. These 
heterogonous practices are also likely to create inequitable outcomes in terms of learning for their pupils.

Summing up, the challenges experienced by teachers in transitioning to emergency remote teaching were multidimensional and multifaceted, and involved both access to technological and digital infrastructures for both teachers and pupils, as well as the development of digital competences for teachers, pupils and parents. The ways in which teachers and the educational environment (the school leadership, parents, pupils) responded to these challenges is likely to have an impact on how equitable the educational outcomes for pupils will be in the future and this point is of immense importance for educational equality in Romania and worldwide.

\section{Acknowledgements}

We would like to thank prof. PhD Simona Sava for her involvement in the project, as well as comments on previous drafts of this paper. We would also like to thank senior lecturer PhD Mihaela Mitescu Manea for her involvement in the project, especially in developing the research methodology underlying the present project. We thank senior lecturer PhD Claudia Borca for her help in setting up the tutoring project and keeping in touch with the schools. We would also like to thank the other members of the research team: Flavia Curtuț, Anca Mărgineanu, Nicoleta Iacobescu and Cristian Harașnuic, as well as all the tutors, teachers and principals involved in the project.

\section{References}

Alexandru, M., Cui, I.N, Dobri, C., Ghiță, C., Ionică, M.E., Mușescu A.A., Serea V.L.V., \& Safta-Zecheria, L. (2020). Digital citizenship competences of future education professionals. Revista de Pedagogie, $1,137-156$

Avgerinou, M. D., \& Moros, S. E. (2020). The 5-phase process as a balancing act during times of disruption: Transitioning to virtual teaching at an international JK-5 school. In Ferdig, R.E., Baumgartner, E., Hartshorne, R., Kaplan-Rakowski, R., \& Mouza, C. (Eds.) Teaching, technology, an teacher education during the COVID-19 pandemic: Stories from the field. Waynesfield, NC, USA: Association for the Advancement of Computing in Education (AACE), Jun (15), 583-594.

Botnariuc, P. , Cucoș, C., Glava C., Iancu, D., Ilie, M., Istrate, O., Labăr A.V., Pânișoară, I.O., Ștefănescu, D., \& Velea, S. (2020). Scoala online: elemente pentru inovarea educației. Raport de cercetare evaluativă. București: Editura Universității din București, available online at https://unibuc.ro/wp-content/uploads/2020/05/Scoala Online Raport aprilie 2020.pdf, accessed on 29.10.2020.

Decretul nr. 195/2020 available here http://legislatie.just.ro/Public/DetaliiDocumentAfis/223831, accessed on 10.11.2020.

Di Pietro, G., Biagi, F., Costa, P., Karpinski, Z., \& Mazza, J. (2020). The likely impact of COVID-19 on education: Reflections based on the existing literature and recent international datasets. Luxembourg: Publications Office of the European Union.

Edumanager (2020) 60\% dintre profesori resimt acut stresul generat de lipsa unor ghidări privind adaptarea curriculei la predarea online, available at https://www.edumanager.ro/60-dintre- 
profesori-resimt-acut-stresul-generat-de-lipsa-unor-ghidari-privind-adaptarea-curriculei-lapredarea-online/, accessed on 29.10.2020.

Guvernul României/Comitetul Național pentru Situații Speciale de Urgență (2020) Hotărârea nr. 6 din 09.03.2020 privind aprobarea unor măsuri suplimentare de combatere a noului Coronavirus. Available here http://www.dsu.mai.gov.ro/wp-content/uploads/2020/04/HOT-6.pdf, accessed on 02.11.2020.

Hodges, C., Moore, S., Lockee, B., Trust, T., \& Bond, A. (2020). The difference between emergency remote teaching and online learning. Educause Review, available here https://medicine.hofstra.edu/pdf/faculty/facdev/facdev-article.pdf accessed on 29.10.2020.

Ministerul Educației și Cercetării (2020) Măsuri luate de Ministerul Educației și Cercetării ca urmare a Hotărârii nr. 6 a Comitetului Național pentru Situații Speciale de Urgență (10.Martie 2020) available here https://www.edu.ro/măsuri-luate-de-ministerul-educației-și-cercetării-caurmare-hotărârii-nr-6-consiliului-național, accessed on 02.11.2020.

OMEC 4135. 21.04.2020 (Order of the Minister for Education and Research), available http://legislatie.just.ro/Public/DetaliiDocument/224975, accessed on 29.10.2020.

Paz Morales, M. (2019). Participatory Action Research (PAR) in Education. In Mertler, A.C. (ed.), The Wiley Handbook of Action Research in Education, Hoboken, NJ: John Wiley \& Sons, 317- 342.

Røkenes, F.M., \& Krumsvik, R.J. (2014). Development of student teachers' digital competence in teacher education: A literature review. Nordic Journal of Digital Literacy, 9(4), p. 250-280.

https://www.idunn.no/file/pdf/66738479/development of student teachers digital competence in teac.pdf

Saldaña, J. (2013). The coding manual for qualitative researchers (2nd edition). Los Angeles: Sage.

UNESCO (2020a) Covid-19 Impact on education, data compiled by UNESCO (for the 3rd of May) available https://en.unesco.org/covid19/educationresponse, accessed on 27.10.2020.

UNESCO (2020b) UNESCO COVID-19 education response: how many students are at risk of not returning to school? Advocacy paper, UNESCO Covid-19 Education response, available at https://unesdoc.unesco.org/ark:/48223/pf0000373992, accessed on 29.10.202 